\title{
Are Ballot Order Effects Heterogeneous?
}

\author{
Amy King \\ University of South Australia \\ Andrew Leigh ${ }^{*}$ \\ Australian National University
}

\begin{abstract}
Past studies of ballot order effects have typically focused on the average benefit to a candidate from being placed at the top of the ballot. But it is possible that this simple average may mask systematic differences in how the ballot order effect varies across candidates and voters. To test this, we analyse all Australian federal elections from 1984-2004, a dataset that is an order of magnitude larger than those used in previous ballot order studies. We find that being placed first on the ballot increases a candidate's vote share by about 1 percentage point. As a proportion of their total vote, the ballot order effect is much larger for independents and minor parties than for major parties. The ballot order effect appears to be similar for male and female candidates, and does not show strong trends upwards or downwards over the 20 year period covered by our study. Across electorates, the ballot order effect is higher in places where voters are younger and fluency in English is lower.
\end{abstract}

JEL Codes: D72

Keywords: ballot position, voter rationality, elections, compulsory voting, Australia

\footnotetext{
* Direct all correspondence to Andrew Leigh, Research School of Social Sciences, Australian National University, ACT 0200, Australia. Telephone: 01161261251374. Fax: 0116126125 0182. Email: andrew.leigh@anu.edu.au. Acknowledgments: We are grateful to Murray Goot, Antony Green, Erzo Luttmer, Simon Jackman, Graeme Orr, and two anonymous referees for valuable discussions and comments on earlier drafts, to Robert Pugh for providing us with historical election data, and to Elena Varganova for outstanding research assistance.
} 
It has long been suspected that the order in which candidates' names are placed on a ballot somehow influences the decision-making process of voters. Theories of ballot position have suggested, variously, that candidates benefit from being placed first on the ballot, due to a 'primacy effect', or last on the ballot, due to a 'recency effect' (Koppell and Steen 2004).

These theories are based on the notion that voters are less likely to make rational decisions when presented with a choice of candidates about whom they have little information. When voters are ignorant about a series of candidates they seek other cues, such as name familiarity or a candidate's political party, to assist the decisionmaking process (Miller and Krosnick 1998). In the absence of any such cues, or where voters are ignorant about or ambivalent towards the candidates presented, it has been shown that the ordering of candidates on the ballot influences a voter's decision (Upton and Brook 1975; Bakker and Lijphart 1980; Darcy and McAllister 1990; Brockington 2003; Koppell and Steen 2004; Alvarez, Sinclair and Hasen 2006; Shue and Luttmer 2006).

These studies have not uniformly agreed on the size of the ballot order effect, nor on whether the benefit accrues only to those at the top of the ballot. The type of election may also matter. Ho and Imai (2004) suggest that if a ballot order effect does exist, it tends to affect only local, relatively unpublicised elections or those elections where the candidates are non-partisan or are largely unknown to the voting public.

In the majority of studies however, the 'primacy effect' of first place on the ballot has been shown to deliver the greatest benefit to candidates. Analysing Ohio state 
elections, Miller and Krosnick (1998) suggest that first place increases a candidate's percentage of votes earned by 2.3 percentage points compared with last place on the ballot. Ho and Imai (2004) alternatively show that candidates in non-partisan elections increase their vote share by 3.3 percentage points when listed first on the ballot, while candidates in Democratic or Republic primary races boost their vote by between 2 and 4 percentage points when listed first.

Similarly, the 'donkey vote' has been widely documented in Australian elections. Since Australia uses a preferential voting system (also known as the single transferable vote or automatic runoff system), voters number the candidates in order of preference. Election officials begin the count by sorting ballot papers into piles based on first preference votes. The candidate with the smallest number of votes is then eliminated, and each of the ballot papers which gave a first preference vote to that candidate are assigned to the voter's next preferred candidate. This process continues until one candidate has more than 50 percent of the remaining valid votes. Donkey voting occurs where an indifferent elector votes for candidates in the order that they appear on the ballot (casting a first preference vote for the first candidate, a second preference vote for the second candidate, and so on). Mackerras (1968) estimated the 'donkey vote' effect to be responsible for anywhere between 1 and 3 percent of the total formal vote cast in Australia.

What makes the Australian situation particularly interesting is that voting is compulsory. In most other democracies, voters may simply choose to stay home on election day (as an increasing number have chosen to do in recent decades: International IDEA 1997:77). By contrast, Australia levies a fine on any citizens who 
do not vote. At the time of writing, the fine was $A \$ 20$, approximately the average hourly wage (Australian Electoral Commission 2006b). Since around 95 percent of adult citizens vote, the Australian case provides an opportunity to estimate ballot order effects across the full population, not merely across the subpopulation who choose to go to the polls in countries with voluntary voting. ${ }^{1}$

Prior to 1984, the ballot order of candidates in Australian Federal House of Representative elections was determined by alphabetic order. Mackerras (1970) has shown that due to firm belief in the power of the 'donkey vote' and a desire to maximize their candidates' chance of being placed high in the ballot order, political parties actively chose candidates with surnames early in the alphabet (see also Orr 2002). Using data from the 1974, 1977 and 1980 Australian federal elections and the 1974 British general election, Kelley and McAllister (1984) estimated that having a surname in the first third of the alphabet was worth an additional 1.3 percentage points for Australian candidates, but had no effect on British election candidates. They conclude that one possible explanation for this difference may be the fact that voting is compulsory in Australia but not in Britain. ${ }^{2}$

\footnotetext{
${ }^{1}$ According to data produced by the Australian Electoral Commission, the turnout rate in the 1984-2004 elections ranged from 93.8-95.8\% (measured as a share of enrolled voters). Judging from years in which Australia held both a Census and a federal election, there does not appear to be an enrollment gap. The number of enrolled voters exceeded the number of adult citizens by $0.8 \%$ in 1996, and by $3.2 \%$ in 2001 (though the latter may be explained by the fact that the census was held in August, and the election in November). Among those who voted, the share who cast an informal vote (either accidentally, or because they deliberately spoiled their ballot paper) ranged from 3.0-6.3\%.

${ }^{2}$ More recently, Jackman (2005) analysed the factors affecting the swing towards or away from candidates between the 2001 and 2004 elections, and concluded that a one position movement up the ballot paper was associated with a 0.13 percentage point increase in vote share.
} 
Partly as a result of such studies, Australian House of Representatives elections switched from alphabetical to random ballot ordering in $1984 .^{3}$ So far as we are aware, this is the first comprehensive study since the advent of randomization to test the effect of ballot order in Australian federal elections. Using Australian data has three advantages: first, randomization creates an ideal natural experiment on the effect of ballot order (as distinct from the alphabetic analysis that has been conducted with respect to other countries). Second, because Australia was one of the first countries to randomize ballot order, we have data from a larger number of elections than any other study of which we are aware (eg. our sample size is nearly 20 times larger than that of Ho and Imai 2004). And third, because voting in Australia is compulsory, we are able to observe the effect of ballot order for the typical citizen (as distinct from the typical voluntary voter).

Using a very large dataset of elections conducted with random ballot ordering, our aim is to estimate the size of the ballot position effect (which we define as being placed at the top of the ballot), and to see how this effect varies across time, across different types of candidates, and according to voter demographics. To preview our results, we estimate that the ballot position effect in Australian federal elections is in the order of 1 percentage point - a figure that appears to be stable over time, and does not appear to differ for male and female candidates. However, as a proportion of the total vote, the ballot order effect is much larger for smaller parties and independents. Comparing across electorates, we find that in areas where the median age is lower,

\footnotetext{
${ }^{3}$ A process of double randomization is used to determine ballot order. The Divisional Returning Officer first allocates a number to each of the candidates listed (wooden balls consecutively numbered are drawn by lot from a rotating container), before a second number is listed alongside the candidates' names assigning them a place on the ballot (the same wooden balls are returned to the container and then re-drawn to assign the second set of numbers) (Australian Electoral Commission 2006a).
} 
and where fewer people are fluent in English, there is a larger premium to topping the ballot paper.

The remainder of our paper is structured as follows. The next section estimates the magnitude of the 'basic' ballot order effect, and analyses whether it has changed over time. The following section tests whether ballot order effect differs according to characteristics of the candidate or the voter. We conclude with a discussion of the implications of our results for election outcomes.

\section{How Large Is the Ballot Order Effect?}

This study uses data from the eight Federal elections to the Australian House of Representatives between 1984 and 2004 (1984 was the first federal election in which ballot position was randomised). There were 148 House of Representatives seats in the federal elections from 1984-1990 and 1996-1998; 147 seats in 1993; and 150 seats in the 2001 and 2004 elections. Between 2 and 14 candidates contested each seat. In total, our sample covers 1187 separate contests and 7113 candidate $\times$ election observations. Since 995 candidates in the sample ran for office more than once, there are a total of 5430 different individuals in the sample. Table 1 presents summary statistics. 


\begin{tabular}{lccc}
\hline Table 1: Summary Statistics & & & \\
\hline Variable & Mean & SD & N \\
Vote share & 0.1669 & 0.1934 & 7113 \\
Log(Vote share) & -2.7893 & 1.6129 & 7113 \\
First Position & 0.1669 & 0.3729 & 7113 \\
Female Candidate & 0.2412 & 0.4278 & 7090 \\
Share of Electorate Not & & & \\
Fluent in English & 2.4295 & 3.1217 & 7113 \\
Median Age in Electorate & 34.2382 & 2.6065 & 7113 \\
Median Weekly Family & & & \\
Income in Electorate & 811.0403 & 209.0128 & 7113 \\
\hline
\end{tabular}

Throughout this paper, our dependent variable is a candidate's share of the primary vote. Although we have data on the full preference distribution in each seat, we do not exploit this feature of our data. This is because parties play a major role in affecting preference ordering, through their use of 'How to Vote' cards. To reduce the risk that voters will accidentally spoil their ballot, these cards frequently number down the ballot. Therefore, without comparing the parties' recommended preference ordering with the actual results in each seat, we would be unable to distinguish so-called 'donkey voting' from voters merely following their party’s recommendation.

We use two variations on the dependent variable: the actual vote share and $\log ($ vote share). Note that each assumes a different functional form for the ballot order effect. Using the vote share assumes that being at the top of the ballot has the same percentage point effect. For example, a 1 percentage point effect means that a candidate who would otherwise have received 10 percent of the vote receives 11 percent, while a candidate who would otherwise have received 50 percent of the vote receives 51 percent. 
By contrast, using $\log$ (vote share) assumes that being at the top of the ballot has the same percentage effect. For example, a 10 percent effect means that a candidate who would otherwise have received 10 percent of the vote receives 11 percent, while a candidate who would otherwise have received 50 percent of the vote receives 55 percent. Theory offers little guidance as to which of these measures should be preferred, so we test both, and allow the data to tell us which is most appropriate.

Our main specification is as follows:

Voteshare $_{i j s t}=\beta$ FirstPosition $_{i j s t}+C_{j t}^{\text {TotalCandidates }}+I_{t}^{\text {Election }}+I_{s}^{\text {Party }}+\varepsilon_{i j s t}$

Where $\mathrm{i}, \mathrm{j}, \mathrm{s}$, and t index candidates, electorates, parties, and elections respectively, FirstPosition is an indicator which is 1 if the candidate is on the first position of the ballot, and zero otherwise, $C^{\text {TotalCandidates }}$ is a vector of indicators for the number of candidates standing in the electorate (since more candidates will mechanically reduce the vote share), $I^{\text {Party }}$ is a vector of party indicators, $I^{\text {Election }}$ is a vector of election indicators, and $\varepsilon$ is a normally-distributed mean-zero error term. All specifications are estimated using ordinary least squares. Standard errors are clustered at the electorate $\times$ election level, to allow for the fact that the total vote share of candidates in the same race must sum to 1 .

Since the ballot position is determined randomly, it should be unnecessary to include further controls. Just as in a randomised medical trial, where patients are allocated randomly to a treatment group or a control group, so a system of random ballot 
ordering assigns candidates to the treatment group (in first position on the ballot paper) or the control group (in second position and lower down on the ballot paper).

Ballot order is - by construction - orthogonal to all candidate characteristics. However, as a robustness check, we also estimate specifications with candidate fixed effects. This specification is identified only from within-candidate variation, using the 995 candidates who ran for office more than once during this period.

Voteshare $_{i j s t}=\beta$ FirstPosition $_{i j s t}+C_{j t}^{\text {TotalCandidates }}+I_{t}^{\text {Election }}+I_{s}^{\text {Party }}+I_{i}^{\text {Candidate }}+\varepsilon_{i j s t}$

Note that we would not necessarily expect the coefficient on first position to be the same in a specification with candidate fixed effects, due to the potential for attrition from the sample. For example, if candidates are more likely to run again when they are placed first on the ballot, this will lead to an underestimate of the true ballot order effect.

Table 2 presents the results from these specifications. In Panel A, the dependent variable is vote share. On average, we estimate that being at the top of the ballot boosts a candidate's vote share by about 1 percentage point. When we estimate ballot order effects using only within-candidates variation, we find a smaller impact of being in first place: just 0.5 percentage points.

In Panel $\mathrm{B}$, we use $\log ($ vote share) as the dependent variable. We find that being in the first position on the ballot boosts a candidate's share of the vote by 28 percent. When we estimate ballot order effects using only within-candidates variation, the 
effect of being at the top of the ballot is to raise a candidate's vote share by 17 percent. The $\mathrm{R}^{2}$ is higher when the dependent variable is the log of the vote share (Column 1 of Panel B) than when it is the level of the vote share (Column 1 of Panel A), suggesting that on average, the log specification better fits the data. We return to this issue below.

\section{Table 2: Basic Ballot Order Effects}

(1)

Panel A: Dependent Variable is Vote share

\begin{tabular}{lcc}
\hline First Position & $0.0097^{* * *}$ & 0.0047 \\
Total Candidates FE & {$[0.0032]$} & {$[0.0054]$} \\
Election FE & Yes & Yes \\
Party FE & Yes & Yes \\
Candidate FE & Yes & Yes \\
Observations & No & Yes \\
R-squared & 7113 & 7113 \\
Panel B: Dependent Variable is Log(Vote share) & 0.99 \\
First Position & $0.2813^{* * *}$ & \\
& {$[0.0196]$} & $0.1748^{* * *}$ \\
Total Candidates FE & Yes & {$[0.0434]$} \\
Election FE & Yes & Yes \\
Party FE & Yes & Yes \\
Candidate FE & No & Yes \\
Observations & 7113 & Yes \\
R-squared & 0.84 & 7113 \\
\hline
\end{tabular}

Note: Standard errors, clustered at the electorate $\times$ election level, in brackets. ***,** and $*$ denote statistical significance at the $1 \%, 5 \%$ and $10 \%$ levels respectively.

Do these effects vary over time? If donkey voting arises from a lack of information, then the rising educational levels in Australia over the period 1984-2004 should cause the effect to decline. ${ }^{4}$ On the other hand, if donkey voting reflects voter apathy, then one might think that just as turnout levels have fallen in many other democracies, the equivalent under compulsory voting might be a rise in donkey voting over time.

\footnotetext{
${ }^{4}$ For example, the share of Australian adults with less than a high school education declined from 73 percent in the 1981 census to 54 percent in the 2001 census.
} 
To test this theory, we interact the first position indicator with a dummy variable for each election. With categorical data, there are two ways of estimating a model with interactions. Suppose we wish to look at how FirstPosition varies across K elections. One approach is to include the FirstPosition variable, plus interactions of FirstPosition with K-1 of the election indicators.

$$
\begin{aligned}
& \text { Voteshare }_{i j s t}=\beta_{0} \text { FirstPosition }_{i j s t}+\sum_{t=1}^{K-1}\left(\beta_{k} \text { FirstPosition }_{i j s t} * I_{t}^{\text {Election }}\right)+ \\
& C_{j t}^{\text {TotalCandidates }}+I_{t}^{\text {Election }}+I_{s}^{\text {Party }}+\varepsilon_{i j s t}
\end{aligned}
$$

Equivalently, we can omit the FirstPosition variable, and include interactions of FirstPosition with $\mathrm{K}$ election indicators.

$$
\begin{aligned}
& \text { Voteshare }_{i j s t}=\sum_{t=1}^{K}\left(\beta_{k} \text { FirstPosition }_{i j s t} * I_{t}^{\text {Election }}\right)+C_{j t}^{\text {TotalCandidates }}+ \\
& I_{t}^{\text {Election }}+I_{s}^{\text {Party }}+\varepsilon_{i j s t}
\end{aligned}
$$

In equation (3), the coefficients on the interaction terms show how ballot order effects differ across elections. In equation (4), each interaction coefficient shows the magnitude of the ballot order effect in that election. We opt for the latter approach, and also provide a formal test of the hypothesis that the ballot order effect is the same in all elections. Other interaction specifications in this paper (except for those in Table 6, where the interacted variable is continuous) follow a similar approach.

The results from this specification are shown in Table 3. Using vote share as the dependent variable, the first position effect is positive in all elections except 2001, 
and largest in 1990 and 1998. We then test two hypotheses: that the ballot order effect is unchanged over time, and that the ballot order effect is not systematically trending upwards or downwards. The first is simply an F-test that the eight first position coefficients are equal, while the second involves running another regression with (First Position $\times$ Year) used in place of the individual election interactions. With vote share as the dependent variable, the F-tests do not reject the hypothesis that the first position effect is the same in all elections, and is not trending upwards or downwards ( $\mathrm{P}=0.12$ for equality; $\mathrm{P}=0.13$ for a linear trend).

With $\log$ (vote share) as the dependent variable, the first position effect is statistically significant in all elections, and largest in 1993 and 2004. In this case, it is possible to reject the hypothesis that the ballot order effect remains constant over time $(\mathrm{P}=0.02)$, but while the effect does seem to fluctuate, it is not systematically trending upwards or downwards. A second F-test cannot reject the absence of a significant linear trend in the log ballot order effect $(\mathrm{P}=0.16)$. 
Table 3: Do Ballot Order Effects Differ Across Elections?

Dep Var:

Vote share

First Position * 1984

First Position * 1987

First Position * 1990

First Position * 1993

First Position * 1996

First Position * 1998

First Position * 2001

First Position * 2004

Total Candidates FE

Election FE

Party FE

Observations

R-squared

F-Test. H0 is that all First Position

coefficients are equal

F-Test. H0 is no linear time trend in

First Position effect
0.0197

[0.0124]

0.0028

[0.0117]

$0.0303 * * *$

[0.0097]

0.0034

[0.0083]

0.0069

[0.0073]

$0.0156^{* *}$

[0.0080]

$-0.0022$

[0.0056]

0.0025

[0.0068]

Yes

Yes

Yes

7113

0.80
(1)

(2)

Dep Var:

Log(Vote share)

$0.2374 * * *$

[0.0597]

$0.1321 * *$

[0.0632]

$0.3318^{* * *}$

[0.0582]

$0.3641 * * *$

[0.0571]

$0.2716^{* * *}$

[0.0432]

$0.3502 * * *$

[0.0542]

$0.1813 * * *$

[0.0474]

$0.3638 * * *$

[0.0563]

Yes

Yes

Yes

7113

0.84

2.46

$\begin{aligned} & 1.65 \\ & \mathrm{P}=0.12\end{aligned}$

2.36

$\mathrm{P}=0.02$

$\mathrm{P}=0.13$

2.02

Note: Standard errors, clustered at the electorate $\times$ election level, in brackets. ${ }^{* * *},{ }^{* *}$ and ${ }^{*}$ denote statistical significance at the $1 \%, 5 \%$ and $10 \%$ levels respectively. Note that the main effect of first position is omitted, because the ballot order effect is interacted with all election indicators. The second F-test is from a separate regression, testing the significance of the coefficient on (First Position $\times$ Year).

\section{Does the Ballot Order Effect Differ Across Candidates or Voters?}

In this section, we test whether the ballot order effect differs across candidates or voters. To compare across candidates, we estimate ballot order effects between parties, and then between male and female candidates. To compare across voters, we test whether a relationship emerges between the demographic characteristics of the electorate and the strength of the ballot order effect. 
First, we ask, is the ballot position effect constant across parties? One factor that might cause differences is the fact that major and minor parties have very different baseline votes. Another is the higher public prominence of major party candidates which may mean that ballot order is less salient for them than for minor party and independent candidates. Our data allow us to explore differences across parties, but unfortunately do not allow us to distinguish between these explanations. ${ }^{5}$

To test for differences across parties, we divide parties into three groups: major parties (the Australian Labor Party, Liberal Party and National Party), minor parties (the Australian Democrats and the Australian Greens), and candidates from smaller parties or running as independents. The mean vote share of the three groups is 39 percent, 6 percent, and 3 percent, respectively. As with election effects, we then interact the first position indicator with an indicator for being from one of these three party groups.

The results are presented in Table 4. Using vote share as the dependent variable, the effect of being first on the ballot is between 0.7 and 1.1 percentage points, and we cannot reject the hypothesis that ballot order effects are identical across major party, minor party, and independent candidates. However, when the dependent variable is $\log$ (vote share), the effect of being first on the ballot is indistinguishable from zero for major parties, 27 percent for minor parties, and 61 percent for independents. An F-test easily rejects the hypothesis that these effects are the same.

\footnotetext{
${ }^{5}$ To distinguish between these two theories, one would need some variation in candidates' prominence that was unrelated to their baseline vote.
} 
Even interacting the ballot order effect with party groups, the $\mathrm{R}^{2}$ is higher in the logged specification than the unlogged specification, indicating that the latter is a better fit to the data. To explore this issue further, we separately estimated the regression for each group of parties (full results not shown). For major parties and independents, the $\mathrm{R}^{2}$ from the logged specification was substantially higher than in the unlogged specification, while for minor parties, the $\mathrm{R}^{2}$ was similar in most specifications. ${ }^{6}$ This suggests that even if one were to focus only on large parties, or only on independents, using logged vote share as the dependent variable would provide a better fit to the data than using the unlogged vote share.

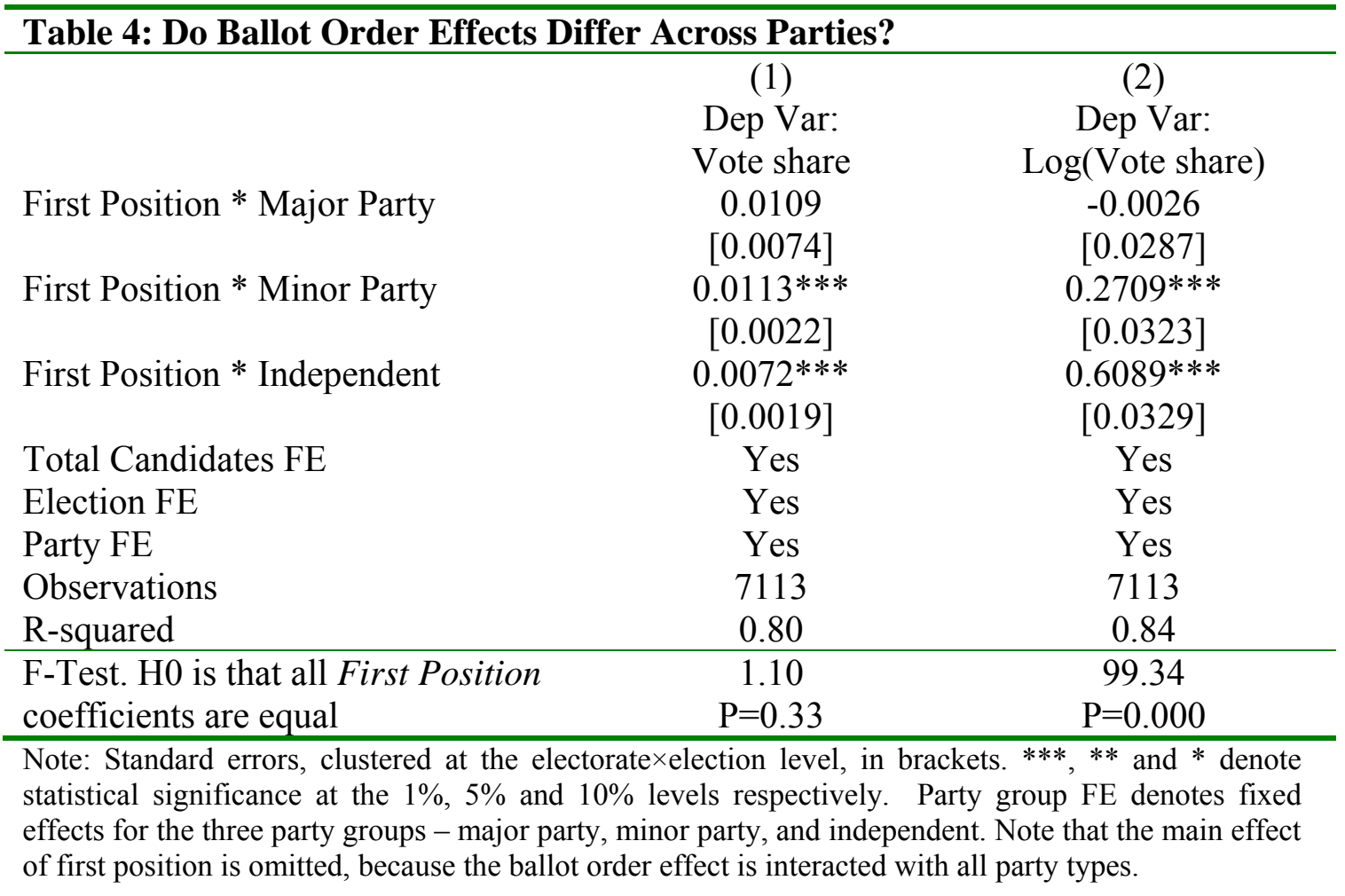

Next, we test whether ballot order effects differ across male and female candidates, by interacting the effect of being in first position with being a female candidate. We

\footnotetext{
${ }^{6}$ For major parties, the $\mathrm{R}^{2}$ was 0.18 (unlogged) and 0.31 (logged). For minor parties, the $\mathrm{R}^{2}$ was 0.39 (unlogged) and 0.35 (logged). For independents, the $\mathrm{R}^{2}$ was 0.40 (unlogged) and 0.56 (logged).
} 
identify male and female candidates using their first name, cross-checking with publicly available records for names that are used by both genders. In this manner, we are able to identify the gender of all but 23 candidates (most of whom listed only their initials on the ballot paper).

The effects of first position for male and female candidates are shown in Table 5. Note that our focus here is not on the raw gender gap, but on the relative benefit that male and female candidates get from heading the ballot. In separate work, we directly analyse the differences between the electoral performance of male and female candidates (King and Leigh 2007).

Looking at all candidates (Panel A), we find no significant gender difference in ballot position, with both male and female candidates obtaining about a 1 percentage point (or 30 percent) increase in their vote from being placed atop the ballot paper. To take account of the fact that female candidates are more likely to represent minor parties, we then split the sample and analyse only major party candidates (Panel B), and only minor party candidates (Panel C). Again, we find no evidence that the ballot order effect differs systematically for men and women, with P-values well above 0.1 on the F-test for equality of the gender coefficients. 


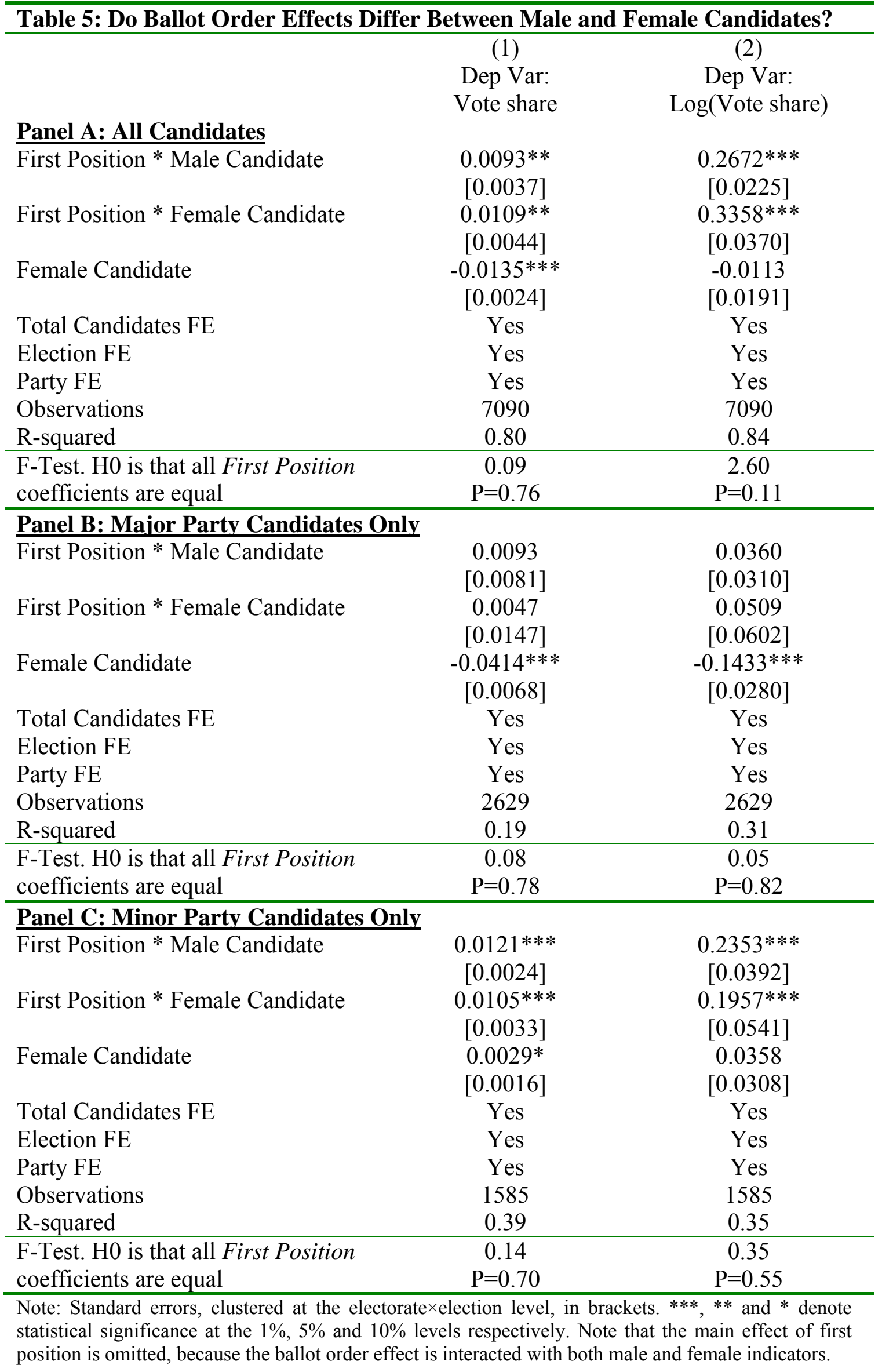


Finally, we attempt to better understand ballot order effects by looking at whether there is any relationship between electorate-level demographics and the ballot order effect. We test three hypotheses about why people might be more likely to vote for the candidate who heads the ballot paper:

- it reflects an inability to distinguish the parties and/or candidates, and is therefore higher in electorates where fewer voters speak English;

- it arises from uncertainty over the lifecycle, and is therefore lower in older electorates; and/or

- it is due to a disenchantment with the political outcomes produced, and is therefore lower in richer electorates.

Ideally, we would like to be able to know each voter's demographic characteristics, and whether he or she voted for the first candidate on the ballot. However, because voting is secret, this information is not available. We therefore use demographic information about the electorate as a proxy for the individual voter's characteristics. Doing so increases the potential that a researcher will attribute ballot order effects to the wrong trait, or commit the so-called 'ecological fallacy'. Suppose we were to observe that the ballot order effect is stronger in an electorate where there are more voters with Trait $X$. This might be because: (a) Trait $X$ causes voters to prefer the first candidate on the ballot; (b) individuals with Trait $X$ are more likely to have unobserved Trait $Y$, which causes voters to prefer the first candidate on the ballot; or (c) people who live in neighbourhoods where more residents have Trait $X$ tend to have Trait $Z$, which causes people to vote for the first candidate on the ballot. Given the impossibility of obtaining individual-level voting data, it is hard to see how these 
limitations can be surmounted. Nonetheless, these limitations should be borne in mind when interpreting the results below.

Electorate-level characteristics are taken from the 1996 and 2001 censuses, matched onto electorates by Kopras $(1998,2003)$. The geographic match is quite precise, since the match is done at the collection district level. For earlier elections, we match using the 1996 census characteristics (within electorates, demographic characteristics are very stable over time). For electorates abolished prior to 1998, we assign the demographics of the closest electorate existing in $1998 .{ }^{7}$ Election fixed effects ensure that the estimation is unaffected by demographic changes over time. For ease of interpretation, all demographic characteristics are normed to a mean of zero and a standard deviation of unity. Since the demographic characteristics for each electorate are held constant over time, standard errors are clustered at the electorate level (rather than the electorate $\times$ election level, as in other specifications).

Table 6 shows the results of the demographic interactions. In general, the sign of the coefficients accords with the hypotheses: the first position effect is larger in electorates with more non-English speaking voters (significant in the log specification), and smaller in older electorates (significant in both specifications). The income of the electorate is not systematically related to the ballot order effect. When all three interactions are included together, only the age effect is significant in the vote share specification; and only the non-English speaking voter interaction is significant in the log vote share specification. Both these effects are quantitatively as

\footnotetext{
${ }^{7}$ Respectively, we use the characteristics of the electorate of Fraser for Namadgi (ACT); Berowra for Dundas (NSW); Hindmarsh for Hawker (SA); Hotham for Henty (Vic); Grayndler for Phillip (NSW); Barton for St. George (NSW); and La Trobe for Streeton (Vic).
} 
well as statistically significant. In the vote share specification, a one standard deviation increase in the age of the electorate ( 3 years) halves the ballot order effect. In the log vote share specification, a one standard deviation increase in the share of the electorate that is not fluent in English (3 percentage points) reduces the ballot order effect by about one-quarter.

\section{Table 6: Do Ballot Order Effects Differ Across Demographic Groups?}

\section{(1)}

Panel A: Dependent Variable is Vote share

\begin{tabular}{lcc}
\hline First Position & $0.0097^{* * *}$ & $0.0096^{* *}$ \\
& {$[0.0032]$} & {$[0.0032$} \\
First Position * Non-English & 0.0022 & \\
& {$[0.0033]$} & \\
First Position * Median Age & & $-0.0055^{*}$ \\
& & {$[0.0027]$} \\
First Position * Median Income & & \\
& & \\
Main effects of demographics & Yes & Yes \\
Total Candidates FE & Yes & Yes \\
Election FE & Yes & Yes \\
Party FE & Yes & Yes \\
Observations & 7113 & 7113 \\
R-squared & 0.80 & 0.80
\end{tabular}

\section{Panel B: Dependent Variable is $\log ($ Vote share)}

\begin{tabular}{|c|c|c|c|c|}
\hline First Position & $\begin{array}{c}0.2813 * * * \\
{[0.0201]}\end{array}$ & $\begin{array}{c}0.2806^{* * *} \\
{[0.0206]}\end{array}$ & $\begin{array}{c}0.2822 * * * \\
{[0.0207]}\end{array}$ & $\begin{array}{c}0.2815^{* * *} \\
{[0.0200]}\end{array}$ \\
\hline First Position * Non-English & $\begin{array}{c}0.0696 * * * \\
{[0.0155]}\end{array}$ & & & $\begin{array}{c}0.0636 * * * \\
{[0.0162]}\end{array}$ \\
\hline First Position * Median Age & & $\begin{array}{c}-0.0389 * * \\
{[0.0178]}\end{array}$ & & $\begin{array}{c}-0.0255 \\
{[0.0182]}\end{array}$ \\
\hline First Position * Median Income & & & $\begin{array}{c}0.0263 \\
{[0.0227]}\end{array}$ & $\begin{array}{c}0.0198 \\
{[0.0218]}\end{array}$ \\
\hline Main effects of demographics & Yes & Yes & Yes & Yes \\
\hline Total Candidates FE & Yes & Yes & Yes & Yes \\
\hline Election FE & Yes & Yes & Yes & Yes \\
\hline Party FE & Yes & Yes & Yes & Yes \\
\hline Observations & 7113 & 7113 & 7113 & 7113 \\
\hline R-squared & 0.84 & 0.84 & 0.84 & 0.84 \\
\hline
\end{tabular}


Our finding that ballot order effects are larger in electorates where fewer voters are fluent in English accords with the cross-country results of Miller and Krosnick (1998), who have shown that ballot order effects are stronger in countries where voters are less knowledgeable about politics. Intuitively, it makes sense that the lower the information or understanding about a set of candidates and their policies, the greater the chance that cues such as ballot order will influence the decision making process of voters.

\section{Conclusion}

The decision by the Australian parliament to switch in 1984 from an alphabetically ordered ballot to randomised ballot ordering was in recognition of the existence of this ballot order effect and the unfair advantage it afforded candidates whose names appeared high in the alphabet. This switch did not abolish ballot order effects - it merely allocated the ballot order effect randomly among those candidates standing for election.

We estimate the effect of being listed first on the ballot in Australian federal elections to be approximately 1 percentage point for the average candidate. Our estimate is similar to past Australian estimates, including Mackerras 1968 (1 to 3 percentage points) and Kelley and McAllister 1984 (1.3 percentage points). Since we find no evidence that the ballot order effect in Australia has risen or fallen over the period 1984-2004, our findings - together with those of earlier studies - suggest that the ballot effect may well have been stable since the 1960s. 
In general, our estimates of ballot order effects are smaller than those that have been observed in the US, by Miller and Krosnick 1998 (2.3 percentage points) and Ho and Imai 2004 (2 to 4 percentage points). The larger ballot order effects in the US seem to assuage the concern of Kelley and McAllister (1984) that compulsory voting in Australia may lead the ballot order effects to be larger than in Britain or the US. Related to this is the criticism that suggests compulsory voting merely raises the number of disinterested or ignorant voters going to the polls. Our results indicate that (at least relative to the US) this has not been the case for compulsory voting in Australia.

The presence of any statistically significant ballot order effects is at odds with a model of perfectly rational voters. Rational voter models suggest that voters should reward candidates who perform well, but should ignore factors such as ballot ordering, which are unrelated to performance. This motivated our analysis of whether ballot order effects differ systematically across candidates or voters.

Across parties, we find that ballot order has a similar effect in the linear specification, but a larger effect on minor parties and independents in the log specification (either because their baseline share of the vote is lower, or because the 'cue' of ballot order matters less for prominent major party candidates). Although the logged specification is less intuitive, it does provide a better fit to the data (ie. a higher $\mathrm{R}^{2}$ ), suggesting that ballot order studies should at the very least show models with both logged and unlogged vote share as the dependent variable. 
We also observe that the effect of being first on the ballot is higher in younger electorates, and in electorates where fewer people are fluent in English. This is consistent with younger voters and migrant voters being more susceptible to ballot ordering. Such a finding also accords with prior research which has demonstrated that younger voters and overseas-born voters are more likely to switch their vote from one election to the next (Leigh 2005).

How pivotal have ballot order effects been in recent elections? To analyse this issue, we turn to look at the two-party preferred vote, which is the salient indicator of the winning margin in a preferential voting system. In the 1996, 1998, 2001 and 2004 Australian elections, 6.7 percent of contests ( 40 out of 595) were decided by a margin that was smaller than our estimated effect of being placed first on the ballot (1 percentage point). If a candidate from one of the major parties had been placed first on the ballot in these elections, our results imply that it would have changed the outcome.

In particular, we are able to identify five contests in recent Australian history where a major party candidate was placed first on the ballot and won by a margin of less than 1 percentage point. We list below our best estimates of the 'lucky' beneficiaries of ballot order effects since 1996, with their share of the two-party preferred vote in parentheses:

- Andrea West, the Liberal Party candidate for Bowman in 1996 (50.9\%)

- Kim Beazley, the Labor Party candidate for Brand in 1996 (50.2\%)

- Michael Lee, the Labor Party candidate for Dobell in 1996 (50.1\%)

- Gary Nairn, the Liberal Party candidate for Eden-Monaro in 1998 (50.2\%) 
- Paul Neville, the National Party candidate for Hinkler in 1998 (50.3\%)

While this is a small list, it does suggest that ballot order has had an effect on the course of Australian political history. Had Kim Beazley not been randomly selected for the first position on the ballot in 1996, it is quite possible that he would not have been in a position to serve as the Leader of the Opposition in 1996-2001 and 2005-2006.

Finally, our results suggest a possible reform to the Australian system for conducting federal elections. While the present system of random ballot ordering is fair before the ballot draw occurs (since every candidate has the same chance of heading the ballot), it is manifestly unfair once ballot order has been determined (since the candidate who draws first position is more likely to win). A fairer system would be to print multiple versions of each ballot paper, rotating the ballot positions so that every candidate tops the ballot as often as every other candidate. Such a rotating ballot - presently used in some state and territory elections in Australia, as well as in the 2003 California Recall election - would more accurately reflect underlying voter preferences than the present Australian federal electoral system. 


\section{References}

Alvarez, R.M., Sinclair, B. and Hasen, R.L. (2006), 'How much is enough? The "Ballot order effect", Election Law Journal, 5(1), 40-56.

Australian Electoral Commission (2006a), Candidates' Handbook, [Online, accessed May 13, 2006], http://www.aec.gov.au/ content/Who/candidates/candidates handbook/ballot papers. $\underline{\mathrm{htm}}$

Australian Electoral Commission (2006b), Voting Within Australia - Frequently Asked Questions, [Online, accessed May 13, 2006], www.aec.gov.au/_content/What/voting/faq_general.htm\#2

Bakker, E.A and Lijphart, A. (1980), 'A Crucial Test of Alphabetic Voting: The Elections at the University of Leiden, 1973-1978', British Journal of Political Science, 10(4): 521-525

Brockington, D. (2003), 'A low information theory of ballot position effect', Political Behavior, 25(1), 1-27.

Darcy, R. and McAllister, I. (1990), 'Ballot position effects', Electoral Studies, 9(1), 5-17.

Ho, D.E. and Imai, K. (2004), Shaken, Not Stirred: Evidence on Ballot Order Effects from the California Alphabet Lottery, 1978 - 2002, January 21, Department of Government, Harvard University, Yale Law School, Department of Politics, Princeton University.

International Institute for Democracy and Electoral Assistance (International IDEA) (1997), Voter Turnout from 1945 to 1997: A Global Report on Political Participation, Stockholm.

Jackman, S. (2005), 'Incumbency advantage and candidate quality', in Mortgage Nation: The 2004 Australian Election. Marian Simms and John Warhurst (eds). Perth, Western Australia: API Network/Curtin University of Technology. 335-347.

Kelley, J. and McAllister, I. (1984), 'Ballot paper cues and the vote in Australia and Britain: alphabetic voting, sex and title', The Public Opinion Quarterly, 48(2), $452-$ 466.

King, A. and Leigh, A. (2007), 'Bias at the ballot box? Testing whether candidates' gender affects their vote', Mimeo, Australian National University

Koppell, J.G.S. and Steen, J.A. (2004), 'The effects of ballot position on election outcomes', The Journal of Politics 66(1), 267-281.

Kopras, A. (1998), Electorate Rankings: Census 1996 (1998 boundaries), Background Paper 14 1997-98. Parliament House, Canberra: Department of the Parliamentary Library. 
Kopras, A. (2003), Electorate Rankings: Census 2001 (2003 boundaries), Research Paper 2 2002-03. Parliament House, Canberra: Department of the Parliamentary Library.

Leigh, A. (2005) 'Economic Voting and Electoral Behavior: How do Individual, Local and National Factors Affect the Partisan Choice?' Economics and Politics 17(2): $265-296$

Mackerras, M. (1968), 'The "donkey vote”, The Australian Quarterly, 40(4), 89-92.

Mackerras, M. (1970), 'Preference voting and the "donkey vote"', Politics, 5(1), 6976.

Miller, J.M. and Krosnick, J.A. (1998), 'The impact of candidate name order on election outcomes', The Public Opinion Quarterly, 62(3), 291-330.

Orr, G. (2002), 'Ballot order: donkey voting in Australia', Election Law Journal, 1(4), $573-578$

Shue, K. and Luttmer, E.F.P. (2006), 'Who Misvotes? The Effect of Differential Cognition Costs on Election Outcomes,' NBER Working Papers 12709, NBER: Cambridge, MA.

Upton, G.J.G. and Brook, D. (1975), 'The determination of the optimum position on a ballot paper', Applied Statistics, 24(3), 279-287. 